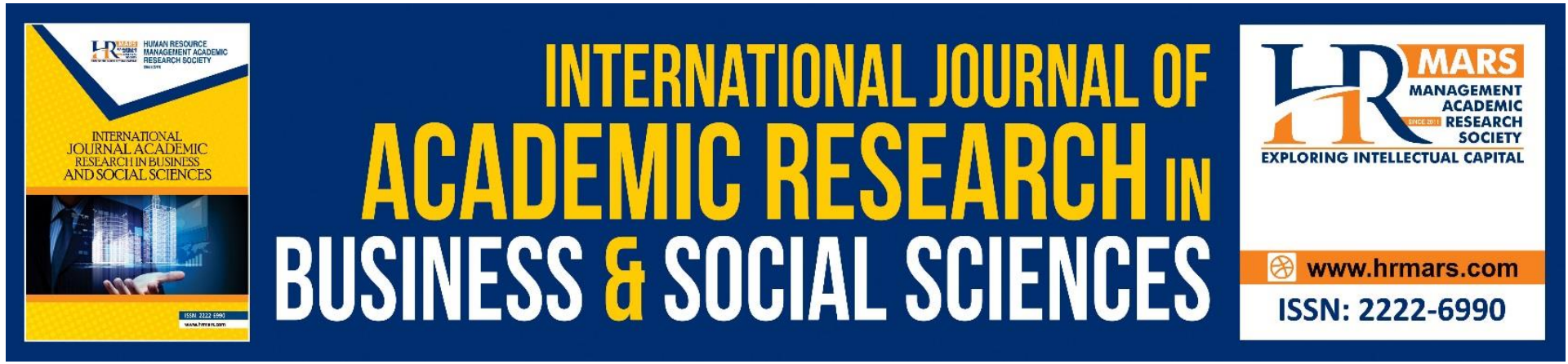

\title{
Impact of Organizational Justice on Job Satisfaction in the Jordanian Pharmaceutical Companies Listed on the Amman Stock Exchange
}

\section{Mahmoud Hussein Abu Joma}

To Link this Article: http://dx.doi.org/10.6007/IJARBSS/v11-i7/10316

DOI:10.6007/IJARBSS/v11-i7/10316

Received: 13 May 2021, Revised: 16 June 2021, Accepted: 02 July 2021

Published Online: 27 July 2021

In-Text Citation: (Joma, 2021)

To Cite this Article: Joma, M. H. A. (2021). Impact of Organizational Justice on Job Satisfaction in the Jordanian Pharmaceutical Companies Listed on the Amman Stock Exchange. International Journal of Academic Research IN Business and Social Sciences, 11(7), 938-959.

Copyright: @ 2021 The Author(s)

Published by Human Resource Management Academic Research Society (www.hrmars.com) This article is published under the Creative Commons Attribution (CC BY 4.0) license. Anyone may reproduce, distribute, translate and create derivative works of this article (for both commercial and non-commercial purposes), subject to full attribution to the original publication and authors. The full terms of this license may be seen at: http://creativecommons.org/licences/by/4.0/legalcode

Vol. 11, No. 7, 2021, Pg. 938 - 959

Full Terms \& Conditions of access and use can be found at http://hrmars.com/index.php/pages/detail/publication-ethics 


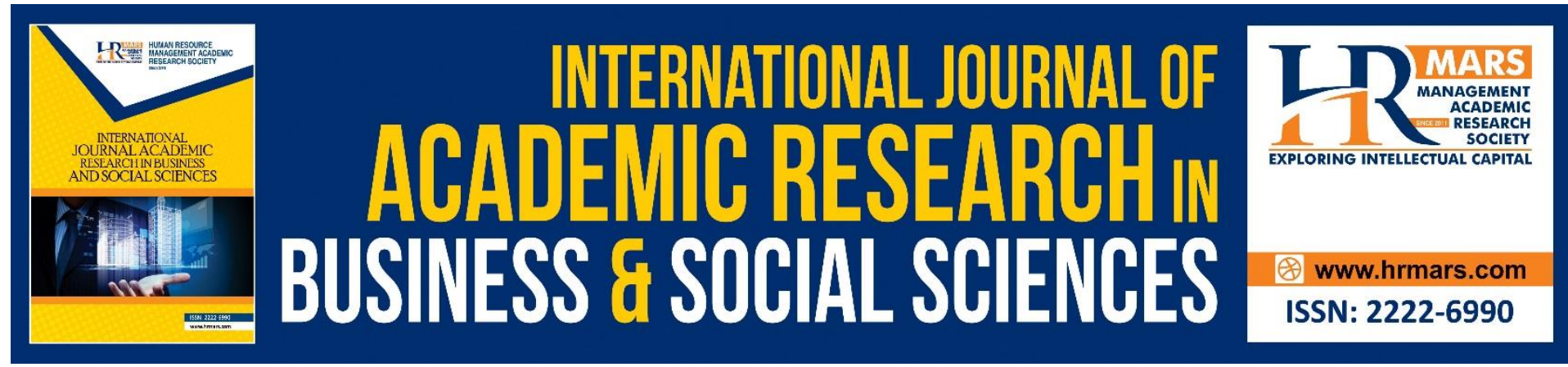

\title{
Impact of Organizational Justice on Job Satisfaction in the Jordanian Pharmaceutical Companies Listed on the Amman Stock Exchange
}

\author{
Dr. Mahmoud Hussein Abu Joma \\ Amman Arab University. Faculty of Business Administration \\ Email: Abujoma@aau.edu.jo
}

\begin{abstract}
The aim of this research is to identify organizational justice and its impact on job satisfaction in the Jordanian pharmaceutical companies listed on the Amman stock exchange, and the problem of the research was the impact of organizational justice dimensions on job satisfaction through the main hypothesis, which is that there is no statistically significant effect of organizational justice with its dimensions (procedural justice, distributive justice, transactional justice $)$ at the level of significance ( $\alpha \quad 0.05 \geq$ ) on job satisfaction with its combined dimensions (training and development, Incentives, work environment) among Amman stock exchange employees. To achieve the goal, the researcher used the descriptive approach, and used the questionnaire as a tool for data collection. The research community consisted of (170) employees working at the biggest three companies of the Jordanian pharmaceutical companies listed on the Amman stock exchange, and (80) male and female employees were selected as a representative random sample of this community by using the SPSS statistical analysis program.

The research found a set of results that there is a medium degree effect between organizational justice with its dimensions (procedural justice, distributive justice, transactional justice) on training and development, and there is a medium degree effect between organizational justice with its dimensions (procedural justice, distributive justice, transactional justice) on Incentives, and it was also found that there is a medium degree effect between organizational justice with its dimensions (procedural justice, distributive justice, transactional justice) on the work environment.

The research also presented a set of recommendations, including: preparing a training plan based on the actual training needs of employees, striving to provide free or semi-free training programs or funded by other parties, taking into account the time factor of the training program, and allowing workers to object to decisions that are unfair to them equally and without discrimination Empowering all employees through participation in committees, internal and external courses, and work teams formed within these companies, for the purposes of transferring knowledge, strengthening ties and social communication between senior management and all employees at their various administrative levels through meetings, meetings, and national and international events, and taking improvement and
\end{abstract}


development measures based on feedback from them, and activating the delegation of powers associated with the tasks of employees at all administrative levels.

Keywords: Organizational Justice, Procedural Justice, Distributive Justice, Job Satisfaction, The Jordanian Pharmaceutical Companies Listed On The Amman Stock Exchange.

\section{The General Framework of the Research}

Institutions of all kinds face many challenges represented in their quest to adapt and adapt quickly to the huge and rapid scientific and technical developments that the world is witnessing.

Despite the repercussions of this development on institutions through their modernization and development of equipment and reliance on technology, the human element is one of the most important actors in it, so the interest in the human element has increased dramatically in this era, as it is one of the most important investments in various institutions.

The modern administration strives to attract efficient and qualified manpower, as it seeks to create and support positive attitudes among the workers, respecting them and treating them in the best way, and trying to achieve a level of justice towards them.

Organizational justice is one of the important and effective concepts that have received the attention of many researchers, as it expresses an important variable in influencing the institution, as it shows its importance in the impact of workers' sense of justice or lack thereof in the workplace, as the worker's sense of justice can lead to a rise in The levels of organizational performance, increasing his confidence in the management of the institution and his conviction of the possibility of obtaining his rights, and what this means of improving the behavior of individuals after reassurance and confidence in the rule of justice in the institution. As for cases in which the worker feels unfair, this has many negative effects such as decreased job satisfaction and performance organizational in general.

Due to the increasing importance of the issue of organizational justice, the application of justice and the values of integrity and impartiality in the organization is considered one of the basic ingredients for forming positive trends for its employees and the ability of the organization to adapt to the events surrounding it.

Among the topics that have been subject to many studies and have received the researchers' attention is job satisfaction because it is linked to the success of the organization. Some of them see that what distinguishes service organizations from industrial organizations is that it depends mainly on the skill of the human element, as the workers are the decisive element in the race to provide the best services and that Availability of skilled cadres is crucial inservice organizations.

Job satisfaction is a personal attitude towards various aspects of a particular job. A worker with a high level of job satisfaction holds positive attitudes towards his job, and thus is not inclined to look for another job or leave the organization. While a worker who is dissatisfied with his job holds negative attitudes about work, he may consider moving to another organization. (Hammadi, 2017)

\section{Research Problem}

By reviewing a number of previous studies by the researcher, such as Othman \& Ali (2019); Fadel \& Fayez (2019); Allawi (2018); Hammadi (2017); Qujah \& Khairi (2020), Jaafara \& AlSharman (2014), Al-Hilalat, Al-Adra \& Al-Darawsheh, 2018), which studied organizational justice and its impact on job satisfaction, it was noted that one of the biggest sources of concern among employees is Fear of inequality, bias and loss of organizational justice, the 
organization's style has become based on favoritism and bias, based on this, and considering that the studied that dealt with this topic were different, either in terms of the dimensions of the variables or in terms of the study population, researcher decided to study the issue of organizational justice and its impact on job satisfaction among employees in the Jordanian pharmaceutical manufacturing companies listed on the Amman stock exchange in order to provide employees with useful information to get rid of the feeling of Anxiety and loss of organizational fairness and consequently affect their satisfaction and productivity.

Scientists and researchers in organizational behavior became interested in studying the subject of job satisfaction, diagnosing its dimensions, clarifying its importance, and working to develop tools to measure it because it has an impact on worker performance and productivity on the one hand, and on worker behavior on the other hand, to consider job satisfaction the worker's attitude towards his job and his organization and its effective impact on achieving worker loyalty. For the organization, which in turn determines the employee's ability to work in the organization and the love of working in it and the extent to which he can continue to work in it. Achieving a high percentage of organizational loyalty is a primary goal that all organizations seek. Achieving organizational loyalty of the worker towards his organization is through his evaluation of the policies followed in the institution, which achieves his satisfaction with the organization that generates a greater incentive towards its work, which contributes to achieving its goals (Qujah and Khairy, 2020). Based on the above and to farther demonstrate the importance of both dimensions' organizational justice and job satisfaction by organizations leaders and researchers; here lies the problem of the research in the presence of a scientific gap in this field in answering the following question: What is the impact of organizational justice on job satisfaction among the employees of the Jordanian pharmaceutical companies listed on the Amman Stock Exchange?

\section{Research Questions}

The main question: What is the impact of organizational justice with its dimensions (procedural justice, distributive justice, transactional justice) on job satisfaction with its combined dimensions (training and development, Incentives, work environment) among the employees of the Jordanian pharmaceutical companies listed on the Amman Stock Exchange? From the main question there are several sub-questions:

1. What is the impact of organizational justice with its dimensions (procedural justice, distributive justice, transactional justice) on training and development for employees of Jordanian pharmaceutical companies listed on the Amman Stock Exchange?

2. What is the impact of organizational justice with its dimensions (procedural justice, distributive justice, transactional justice) on the Incentives of employees of the Jordanian pharmaceutical companies listed on the Amman Stock Exchange?

3. What is the impact of organizational justice with its dimensions (procedural justice, distributive justice, transaction justice) on the work environment of the employees of the Jordanian pharmaceutical companies listed on the Amman Stock Exchange?

\section{Research Objectives}

The research mainly aimed to identify the impact of organizational justice with its dimensions (procedural justice, distributive justice, transactional justice) on job satisfaction with its combined dimensions (training and development, Incentives, work environment) from the perspective of workers in the Jordanian pharmaceutical companies listed on the Amman Stock Exchange, through: 
1. The research aims to identify the reality of employees' understanding of the Jordanian pharmaceutical companies listed on the Amman Stock Exchange of the dimensions of organizational justice.

2. The research aims to determine the level of job satisfaction among workers in the Jordanian pharmaceutical companies listed on the Amman Stock Exchange.

3. The research aims to find out if there is a statistically significant effect between organizational justice and job satisfaction from the point of view of workers in the Jordanian pharmaceutical manufacturing companies listed on the Amman Stock Exchange.

\section{The Importance of the Research}

The research derives its importance from the reality of the importance of the topic it deals with and the goals it seeks to achieve. This importance can be highlighted as follows:

a. Scientific significance (theoretical):

1. This research contributes to raising awareness of the concepts of organizational justice and job satisfaction and raising the interest of senior leaders in the results of applying the concepts of organizational justice and job satisfaction among employees.

2. The importance of this research is clear in its attempt to clarify the impact of organizational justice on job satisfaction, which has become the focus of the officials' attention in organizations as it is the most important factor that helps raise the performance and efficiency of employees.

B. Practical importance:

3. The research may contribute to drawing the attention of officials in the Jordanian pharmaceutical companies listed on the Amman Stock Exchange to the importance of the employees' sense of organizational justice and providing them with suggestions that help increase the level of organizational justice and job satisfaction, which helps in the development of work in the Jordanian companies for pharmaceutical industry listed on the Amman Stock Exchange.

4. This study, with its results, can help enrich the training programs in the Jordanian pharmaceutical companies listed on the Amman Stock Exchange to include the concepts of organizational justice and job satisfaction.

5. The research may contribute to clarifying the positive effects of applying organizational justice on job satisfaction among workers in the Jordanian pharmaceutical manufacturing companies listed on the Amman Stock Exchange.

\section{Research Hypotheses}

(H0.1): There is no statistically significant effect of organizational justice with its dimensions (procedural justice, distributive justice, transactional justice) at the significance level ( $\alpha 0.05$ $\geq$ ) on job satisfaction with its combined dimensions (training and development, Incentives, work environment) among employee's Jordanian pharmaceutical companies listed on the Amman Stock Exchange.

(H01-1): There is no statistically significant effect of organizational justice with its dimensions (procedural justice, distributive justice, transactional justice) at the level of significance $(0.05 \geq \alpha)$ on training and development for employees of Jordanian pharmaceutical companies listed on the Amman Stock Exchange. 
(H01-2): There is no statistically significant effect of organizational justice with its dimensions (procedural justice, distributive justice, transactional justice) at the level of significance $(0.05 \geq \alpha)$ on the Incentives of the employees of the Jordanian pharmaceutical companies listed on the Amman Stock Exchange

(H01-3): There is no statistically significant effect of organizational justice with its dimensions (procedural justice, distributive justice, transactional justice) at the level of significance ( $\alpha$ 0.05 ) on the work environment of the employees of the Jordanian pharmaceutical companies listed on the Amman Stock Exchange

\section{Research Model}

The model shown below shows the links between the independent variable of this research (organizational justice) and the dependent variable (job satisfaction), as well as the relationship between the variables as mentioned in the hypotheses of the study.

The independent variable

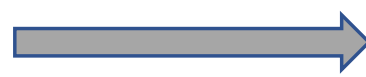

The dependent variable

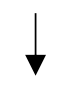

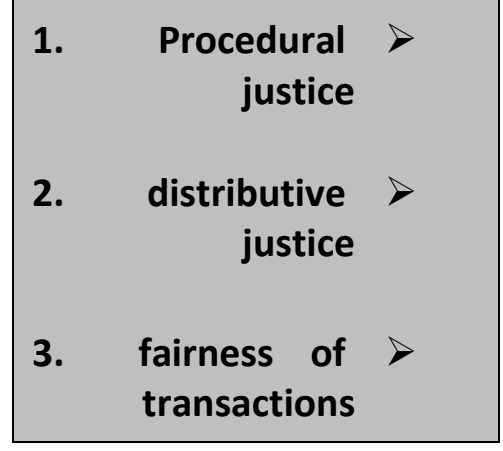

-study model

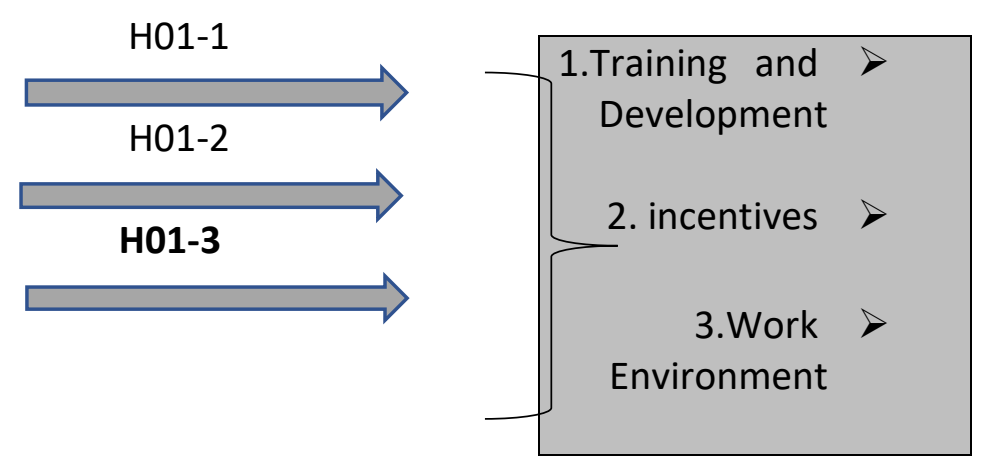

The model was prepared by the researcher based on the sources shown in Table No. (1)

Table No. (1)

\begin{tabular}{|c|c|}
\hline The referenced & The variable \\
\hline (Othman, Ali 2019), (Fadel, Fayez 2019) (Allawi, 2018) & $\begin{array}{l}\text { Organizational justice in its dimensions (procedural justice, distributive justice, } \\
\text { transactional justice) }\end{array}$ \\
\hline $\begin{array}{l}\text { (Hammadi, 2017), (Qujah, Khairi, 2020), (Jaafara, Al-Sharman, 2014), } \\
\text { (Al-Hilalat, Al-Adra, Al-Darawsheh, 2018) }\end{array}$ & $\begin{array}{l}\text { Job satisfaction with its combined dimensions (training and development, } \\
\text { Incentives, work environment) }\end{array}$ \\
\hline
\end{tabular}

\section{Procedural Definitions}

Organizational Justice

Procedural Definition

Organizational justice can be defined as treating all employees of the Service pharmaceutical industry fairly and with utmost integrity and transparency, without bias and favoritism, and 
giving everyone his right, which will be measured through the questionnaire's paragraphs in the Jordanian pharmaceutical companies listed on the Amman Stock Exchange.

The concept of organizational justice includes three dimensions:

\section{a. procedural justice}

Procedural Definition: Procedural justice is defined as the feeling of the employee in the Jordanian pharmaceutical companies listed on the Amman Stock Exchange that the procedures applied by the administration against him in order to obtain his rights are the same as the procedures followed against his colleagues similar to him at work, which will be measured through the paragraphs of the questionnaire in Jordanian pharmaceutical companies listed on the Amman Stock Exchange.

\section{B. distributive justice}

Procedural definition

Distributive justice can be defined procedurally as the feeling of the employee in the Jordanian pharmaceutical companies listed on the Amman Stock Exchange that the wages, bonuses, and compensations offered to him are similar to what is offered to his colleagues similar to him in the level of performance and job level, which will be measured through the paragraphs of the questionnaire in the Jordanian companies for pharmaceutical industry. Listed on the Amman Stock Exchange.

\section{T. fair Dealings}

Procedural definition

Transactional justice is defined as the feeling of the employee in the Jordanian pharmaceutical companies listed on the Amman Stock Exchange that the administration deals with him fairly and that it treats the rest of the employees in the same manner, which will be measured through the questionnaire's paragraphs in the Jordanian companies for pharmaceutical industry listed on the Amman Stock Exchange.

\section{Job Satisfaction}

Procedural definition

Job satisfaction can be defined as the feeling of the employee in the Jordanian pharmaceutical companies listed on the Amman Stock Exchange with satisfaction, reassurance, conviction, and confidence that the service pharmaceutical industry is able to satisfy his desires and needs, which will be measured through the questionnaire's paragraphs in the Jordanian companies for pharmaceutical industry listed on the Amman Stock Exchange.

The concept of job satisfaction includes three dimensions:

a. training and development

Procedural definition

Training and procedural development is defined as providing employees in the Jordanian pharmaceutical companies listed on the Amman Stock Exchange with new skills and experiences and working to develop them to keep pace with everything new to contribute to improving the efficiency of the service pharmaceutical industry employees and improving the quality of service performance provided, which will be measured through the questionnaire paragraphs in Jordanian pharmaceutical companies listed on the Amman Stock Exchange.

B. Stimulus: 
Procedural Definition

Incentives can be defined procedurally as what employees receive in Jordanian pharmaceutical companies listed on the Amman Stock Exchange in return for their efforts, doing their work and providing services. It includes direct financial payments such as wages, salaries, incentives and profits, and indirect payments such as insurances and paid vacations. It is a moral or material allowance, whether in cash or advance A job granted as a Incentive tool by the senior management in return for an effort, behavior, distinguished work, or business performance during and outside official working hours. It contributes to developing the reality of work in the Jordanian pharmaceutical companies listed on the Amman Stock Exchange and improving their image and the level of services provided to the recipients of these services, which will be measured. Its impact through the questionnaire's paragraphs on the Jordanian pharmaceutical companies listed on the Amman Stock Exchange.

\section{T. Work Environment}

Procedural definition

The work environment can be defined procedurally as the prevailing conditions inside and outside the Jordanian pharmaceutical companies listed on the Amman Stock Exchange, which have an impact on the behavior and performance of employees and determine their needs towards work, which will be measured through the questionnaire's paragraphs in the Jordanian companies for pharmaceutical industry listed on the Amman Stock Exchange.

\section{Theoretical Aspect and Previous Studies Introduction}

These variables were searched by the researcher to clarify the impact of organizational justice on job satisfaction in the Jordanian pharmaceutical companies listed on the Amman Stock Exchange. This has an impact on the performance of employees in the Jordanian pharmaceutical companies listed on the Amman Stock Exchange. This part deals with two main axes; The first axis was organizational justice, and the second axis included job satisfaction, then several previous studies were touched.

\section{Organizational Justice}

Researchers in the social sciences and humanities have realized since ancient times the importance and values added by principles of justice within the organization. However, the term organizational justice did not appear until the year (1987) to denote workers' sense of justice and integrity in organizations. justice is an organizational centered around job conditions that lead employees to believe that they are treated fairly or exposed to injustice and inequality. Some researchers believe that the employee evaluates the fairness of a procedure or decision in the organization according to two principles: balance, and correction and balance are done by evaluating the job-related outputs of employees and comparing them with the value of the inputs they provide the organization. As for correction, it is a principle that refers to the quality of the decision or procedure, which makes it They appear fair and appropriate, and to a set of standards that enhance the justice of decisions, such as their application to everyone without exception. It represents the way the organization deals with individuals and represents one of the basic components of the social and psychological structure of the organization. Where it is considered a social value, and a social pattern, and the attack on it by the organization, it is seen as a destruction of the values of the workers 
and their social relations, so unfairness results in the employees' behavior that is harmful to the organization. (Al-Washa'i, 2020)

\section{The Concept of Organizational Justice}

Many researchers point out that the concept of organizational justice is ancient, ancient but it is linked to the name of justice and regulatory law and legitimacy and believe that justice represents the extent to which it is dealing with the justice of workers as well as the output they receive and fair procedures by the organization.

It is also known as a kind of individual or collective awareness of labor laws through familiarity with professional rules and a sense of their just application to all employees. (Abu Libdeh, 2020)

It can also be defined as the organizational activity used to distribute resources and rewards using standardized, accurate and fair procedures, as well as treating workers with respect, ensuring that their individual rights are preserved. (Al-Washa'i, 2020)

\section{Dimensions of Organizational Justice}

The concept of organizational justice is based on three dimensions:

Procedural Justice

It is represented by the employee's sense of the fairness of the procedures followed in determining the outputs, and it is the employee's awareness of the fairness of the procedures and methods used in distributing the inputs and outputs in the organization (Allawi, 2018)

Procedural justice reflects the extent to which employees feel the fairness of the procedures that were used to determine the outputs. It is the mental perception of the justice of the procedures followed in making decisions that affect individuals. This type of justice is achieved when the employee could discuss the foundations and rules based on which his performance will be evaluated, and examples of These procedures are those that are designed to increase participation in decision-making, or through which it seeks to adopt certain procedures to reduce bias and error in the decisions that are taken. The organizational measures that are designed to be objective, fair and difficult to verify unless two conditions are met:

The first condition: that the first two parties who put in place the organizational procedures (the administration) and the second that is affected by those procedures (the workers) agree on the objective bases upon which those procedures are formulated.

The second condition: The first party (the administration) must provide the second party (the workers) with sufficient information on how to implement these procedures.

aspects of procedural justice

Organizational behavior scientists have revealed two aspects of procedural fairness:

\section{Structural Aspect}

Regarding how decisions are made and for us to appear that way is fair, the following must be considered:

- That individuals have a voice in decision-making procedures, meaning that they have a say in making decisions affecting them.

- Giving the opportunity to correct errors.

- Implementing firm rules and policies. 
- Not being biased when making decisions.

\section{Social Aspect}

It relates to the quality of treatment that the worker receives at the hands of decision makers, and the sense is affected by the fairness of that treatment in two ways:

- How true and sufficiency is the information he receives regarding the implementation of decisions

- It relates to social sensitivity, i.e., the extent of attention the individual receives when unsatisfactory results occur in implementing decisions. Evidence indicates that people are more accepting of negative outcomes when they are provided with sufficient and complete information about them (Rahima and Akram, 2020).

Accordingly, procedural justice is the employees' sense of the integrity of the actions taken by the organization towards them and the resulting outcomes.

\section{Distributive Justice}

It is the fairness of the outputs obtained by the employee, so that the individual realizes that he has been fairly rewarded in return for his efforts, and it means the extent to which the outputs (such as income, rewards, tasks and responsibilities, resources, benefits, etc.) are distributed according to the assessment of employees in different organizations (AI Dhafri and Saidia, 2020)

Distributive justice is achieved between individuals when there is equality in the distribution of resources and organizational opportunities among them, and distributive justice is also achieved when the contributions made by the individual to the organization in which he works are linked with what he receives from the rewards offered to him such as: salaries, incentives, promotions, material facilities and work tasks, and that workers feel that they are not Distributive justice creates a kind of tension in the relations between employees and each other on the one hand, and between employees and management on the other.

There are three rules of distributive justice in organizations:

\section{Distribution Base}

It is based on the idea of giving rewards based on contribution, a person who works full time deserves more compensation than

A person who works part-time assuming that other factors are held constant and if the opposite happens, this means that the rule of equality has been exceeded.

\section{Quality Base}

This rule means that all workers, regardless of their characteristics (gender, race, religion) must have equal opportunities to obtain rewards, for example, when the organization works to provide health services to its employees, these services must include all employees within the organization and not only those who work hard, if otherwise, but the rest of the employees will also feel that there is an overstepping of the quality rule.

\section{Base of Need}

This rule is based on the idea of presenting individuals with urgent needs to others to assume that other things are equal, for example if the organization wanted to increase wages, and there was a married woman with children, and there was an unmarried woman. Assuming other things are equal, the married woman should take precedence over the second, and if 
the opposite happens, the married woman feels that the rule of need has been exceeded. (Rahima and Ikram, 2020)

Based on this, distributive justice means that the distributional values of the workers are carried out on a fair basis so that everyone obtains his right.

\section{Fair Dealings}

It is the degree to which employees feel the fairness of the treatment (humanitarian and organizational) that they get when they apply the procedures.

It refers to the extent to which individuals feel the fairness of the treatment they need when the procedures are applied to them, and transactional justice includes two aspects:

- Treatment of individuals by superiors.

- Provide adequate explanation of decisions to the individuals who are affected by them.

Transactional equity has two components:

Personal sensitivity: refers to fair treatment with respect and politeness by superiors to subordinates.

- Explanations or social accounting: It refers to the organization providing reasonable explanations to employees about any unsuitable outputs or rewards being distributed. (Mohammed, 2015)

Considering this, the fairness of dealings means the extent to which employees feel the fairness and integrity of the treatment they receive from their superiors.

\section{Job Satisfaction}

There is still no agreement among researchers about an agreed concept of the meaning of job satisfaction, and the reason for this is due to the difference in research and studies and the multiplicity of scientific fields that have been addressed in the study. Job satisfaction is a purely individual subject, and one person's satisfaction can be the dissatisfaction of another person.

Job satisfaction is defined as the positive emotional state resulting from an individual's evaluation of his job or what he obtains from that job, and this definition means that job satisfaction is achieved if the individual evaluates his job positively and neglects to refer to the thing being evaluated. (The Reah, 2018)

It is also the degree to which the individual achieves his needs within the framework of the overall conditions within which he works. (Bochouareb, 2015)

The researchers presented several concepts closely related to the concept of job satisfaction, which are included in several of their definitions, including the following:

? Job satisfaction and a feeling of happiness: Satisfaction expresses the employee's feeling of happiness when his goal is achieved.

? Satisfaction and level of ambition: Satisfaction is achieved when the job follows the employee's ambitions.

? Satisfaction and expectation: Satisfaction is achieved when the employee's expectations are fulfilled about the returns he gets from and the satisfaction of needs: Satisfaction is achieved when the employee feels that his needs have been satisfied. (Belhadi, 2016).

\section{Dimensions of Job Satisfaction}

The concept of job satisfaction is based on several dimensions, including:

- $\quad$ training and development 
The process of training and development comes after the stage of the process of polarization, selection, and appointment, which is a process that is of great importance in raising the productive efficiency of employees by keeping pace with the development in work methods and improving their skills and abilities on the one hand, and on the other hand changing their behavioral patterns that they follow in the performance of their work. Training is one of the basic pillars of sound management, and it is considered one of the necessary pillars for self- and organizational development, so that the human element becomes more knowledgeable and able to carry out its job tasks in the appropriate and required manner. (Buzrin, 2017).

\section{- $\quad$ Stimulus}

When individuals decide to take a job in an organization, they consider many factors such as working conditions, reputation of the organization, opportunities for training and development, job security, but most of all they focus more on the rewards and incentives for that job, i.e., how attractive the job is. In terms of monetary and non-monetary compensation. The higher the rewards, the better the chance of attracting, utilizing, and retaining the best human resources in the organization.

\section{- Work Environment}

It is a group of elements derived from the overall environment, but which constitute forces that have an impact on the organization and are linked to elements within the organization's borders. The elements from the organized external environment that are related or likely to be linked to setting and reaching goals are also known. They include competitors, consumers, suppliers, customers, organizations that exercise control over the organization and unions different and government. (Belhadi, 2016)

. Types of work environment in organizations:

General work environment, private work environment, external work environment, and internal work environment. (Belhadi, 2016).

\section{Related Previous Studies}

Arabic Studies

Research (Shamma, 2019)

The research aimed to identify the degree of job satisfaction for teachers in Arab public schools within the Green Line, and the effect of gender variables and years of experience on job satisfaction. A teacher and a teacher. To analyze the results, the arithmetic averages and standard deviations were calculated for all areas of the research and its paragraphs, and a triple analysis of variance was used. The results of the research showed that there is a large degree of job satisfaction. The research also showed that there are no statistically significant differences in the degree of job satisfaction due to the gender variable. Considering the results, the research recommended the need to encourage and empower teachers, which increases the degree of job satisfaction and benefits the institution and achieves its goals. this research was used to look at the dimensions of the dependent variable (job satisfaction), which helped build the research model.

Research (The Wind, 2018)

this research aimed to identify the job satisfaction of the teachers of the foundation stage and its impact on improving professional performance in the schools of quality foundation. 
To achieve the goal, the researcher used the descriptive approach and used the questionnaire as a tool for data collection. The research community consisted of (150) teachers of the quality basic teacher. (30) male and female teachers as a representative sample of this community, the researcher followed several statistical methods using the Statistical Analysis Program (SPSS).

The results of the research concluded that the level of job satisfaction was high for teachers at quality schools as a basis, and there was a statistical significance in the level of improvement in the performance of teachers at quality schools as a basis attributed to the factors affecting job satisfaction, and there was a correlation between job satisfaction and the level of professional performance among teachers at quality schools. Quality is a basis, and that there is no correlation between the responses of the sample members on the scale of job satisfaction and the level of professional performance of teachers at quality schools is a basis due to the variables of gender, academic qualification, and years of experience, while there is a correlation between job satisfaction and the level of professional performance due to the training variable. The research recommended working on improving the work climate in schools in general, focusing on improving the relationship between schoolmates and fellow profession at the local level in order to exchange experiences, and focusing on training teachers on a regular basis and enabling them to use modern educational methods, including a significant impact on raising The level of performance and finally the use of objective and scientific methods and procedures in evaluating teachers from a professional point of view, and this research was taken advantage of in looking at the dimensions of the dependent variable (job satisfaction), which helped in building the research model.

Professional Research (2016)

The research aimed to identify the role played by the prevailing organizational justice in the organization in achieving job satisfaction among individuals working at the headquarters of the Shatma municipality. The researcher used in this research the descriptive approach. The research population consisted of all workers at the Shatma municipality headquarters, who numbered (80) individuals, and consisted of the research sample consisted of all employees, which numbered (80) individuals, and the researcher used the questionnaire as a tool for the study.

The results of the research concluded that the level of organizational justice in the institution was average, and there is a positive correlation between justice and job satisfaction, and the research recommended the need to increase moral and material stimuli for all workers in the municipality and also raise the level of justice among workers to increase the level of satisfaction, and this research was taken advantage of in perusal On the dimensions of the dependent variable (job satisfaction), which helped in building the research model.

Studies in English Language

Dodoo Research (2018)

The research aimed to assess the level of job satisfaction among holders of master's degrees in nursing from health care institutions. A cross-sectional research was conducted in randomly selected health care institutions in Poland using job satisfaction.

The researcher used the descriptive analytical method, and the research population consisted of all workers, numbering (111) workers, and the research sample consisted of all workers, numbering (111) workers, and the researcher used the questionnaire as a tool for the study. 
The results of the research concluded that workers with direct relationship with chiefs and other nurses obtained the highest degrees of job satisfaction, and that there is a relationship between job classification and job satisfaction level. The results showed a relationship between internal factors and job satisfaction, and the research recommended focus and attention on what is being done to enhance performance. This research was used to examine the dimensions of the dependent variable (job satisfaction), which helped in building the research model.

Gerald \& Karimi Research (2016)

The research aimed to research the impact of organizational justice and employee function in terms of satisfaction and performance evaluation on the other hand. The research was a cross-sectional research conducted on Bank Melli employees in Iran. The questionnaire was used as a tool to achieve the research tool and was applied to a simple random sample of 248 individuals.

The results of the research concluded that increasing organizational justice leads to an increase in job satisfaction in performance evaluation, and the research recommended that there should be a better understanding, prediction and awareness of human behavior that gives the ability to analyze the relationship between organizational justice and job satisfaction, and expand knowledge in the field of management to a degree Managers know the different ways to create an appropriate environment to enhance organizational justice and enhance employee job satisfaction, which in turn leads to better performance on their part, this research was used to examine the dimensions of the independent variable dependent on the current study.

Jain \& Mathur research (2015)

The research aimed to explore the relationship between organizational justice, employee engagement and job satisfaction among workers in the public sector at the Electricity Board in (Madhya Pradesh) and the Indian Food Corporation. In India, a probability sample of (100) employees were selected, and the researchers used the questionnaire as a tool for the study. The results of the research concluded that if the concept of justice were greater in the organization, the employee's satisfaction would be greater in the job, and that the employee would feel job satisfaction if he did not develop bad feelings about organizational justice.

The research recommended the need to raise the level of awareness of justice in the organization, which will lead to a higher level of job satisfaction and give the individual a sense of satisfaction and that he can depend on the organization, and this research was taken advantage of in looking at the dimensions of the independent variable dependent on the current study.

\section{Methodology and Procedures Research Methodology}

The research will depend on the descriptive analytical approach to test the impact of organizational justice with its dimensions (procedural justice, distributive justice, transactional justice) on job satisfaction with its combined dimensions (training and development, motivation, work environment) among on the Jordanian pharmaceutical companies' employees by reviewing previous relevant studies, and using a questionnaire as a data collection tool, the results of its analysis will cover the practical side of the study. 


\section{Research Population and Sample}

The research population are consisted of employees who are appointed to the upper and middle administration level, in the Jordanian pharmaceutical companies listed on Amman Stock Exchange, whose number is (170) employees. As for the study sample, a random sample of (80) male and female employees had been selected from the total employees from three employees who are appointed to the upper and middle administration level, in the Jordanian pharmaceutical companies listed on Amman Stock Exchange, whose number is (170) employees. As for the study sample, a random sample of (80) male and female employees had been selected from the total employees of the Jordanian companies for the pharmaceutical industries of the Jordanian companies for pharmaceutical industry.

\section{Sources of Data Collection}

Two sources will be used to collect data to achieve the objectives of the study:

Primary sources: The questionnaire will be relied on to obtain the primary data for the research and to address the analytical aspects, as it will be designed and developed based on the proposals of researchers with specialization and previous studies related to the subject of the research and taking the opinion of the arbitrators.

Secondary sources: The theoretical framework for the research will be prepared based on secondary data sources represented by relevant Arab and foreign references, such as books, scientific studies, theoretical and applied studies, university theses, scientific journals, reports issued by specialized institutions, and searching in various electronic databases.

\section{Research Tool}

Researcher developed the research tool represented in the collection of primary data. The questionnaire consists of six parts to collect data. The first part relates to the functional and demographic characteristics of the research sample population (employees), while the second part is a set of questions to measure the independent variable (organizational justice). And its sub-dimensions (procedural justice, distributive justice, transactional justice), and the third part consists of a set of questions to measure the dependent variable (job satisfaction) and its sub-dimensions (training and development, motivation, work environment), and the fourth part is to identify the level of knowledge and knowledge of the staff of. The vision, mission, and strategic objectives of pharmaceutical industry, while the fifth part talks about the level of general evaluation of direct job satisfaction with work in the Jordanian companies for pharmaceutical industry, and the sixth part is knowledge of the suggestions and needs from the point of view of employees to improve the work environment and raise the level of employee satisfaction. Likert quinquennial classification was adopted to measure the impact of justice Organizational dimensions (procedural justice, distributive justice, transactional justice) on job satisfaction with its combined dimensions (training and development, motivation, work environment) for the Jordanian companies for pharmaceutical industry's employees as follows: (very high, high, medium, low, very low) so that each answer takes importance, and then analyzed and tested its hypotheses. The questionnaire was provided and distributed electronically to all members of the sample targeted for the study, in cooperation with the Directorate of Human Resources and the Directorate of information technology, through the e-mail system. 
Statistical Methods used

To answer the research questions and test hypotheses, the data will be processed using the Statistical Package for the Social Sciences: SPSS, where the following statistical analyzes will be used:

Frequencies and percentages to describe the demographic and functional characteristics of the research sample members.

Arithmetic averages and standard deviations of the research tool items and areas.

Internal consistency coefficient (Cronbach Alpha) to verify the stability of the research tool.

Multiple regression analysis in order to measure the effect of the dimensions of the independent variables on one dependent variable.

\section{Statistical Analysis and Results}

Summary of the study

The results of the study showed a medium degree of satisfaction among the employees of the Jordanian companies for pharmaceutical industry with an average of (3.18) points out of 5 on the five-year rating scale for 2021 , with a satisfaction rate of (64.6\%).

\section{Phrase Guide and Rating Scale for Satisfaction Levels}

Likert quinquennial classification was adopted to measure the level of satisfaction of employees in pharmaceutical industry with respect to the independent dimension (organizational justice) applied in the Jordanian companies for pharmaceutical industry.

The general trend of the degree of job satisfaction in pharmaceutical industry according to the axes

The results that the study showed from the reality of the employees' responses to the indicators of the axes measuring job satisfaction indicated that the average general satisfaction reached (3.18) points, as it was classified according to the classification guide for measuring the level of satisfaction that was mentioned previously, and it is noted that all the axes of the study also came in the high to medium level of Satisfaction according to the fivelevel satisfaction rating index.

The first axis (procedural justice)

This axis included (6) indicators that were distributed to measure the level of employee satisfaction with the procedural justice applied in the Jordanian companies for pharmaceutical industry, where the results showed that the level of satisfaction of the staff of pharmaceutical industry about procedural justice in dealing with employees and interest in their performance was medium and with an arithmetic average (3.11) Point, and according to the indicators of this axis, the first indicator, "Procedures for handing over employees to their tasks are carried out in an objective manner" had the highest degree of satisfaction among all indicators of this axis with a mean of (3.39), followed by "I receive a fair reward for the additional efforts I make" with an average of (3.26).

The indicator, which states that "workers are allowed to object to decisions that are unfair to them equally", obtained the lowest degree of satisfaction with a mean of (2.94).

The second axis (distributive justice): 
This axis included (8) indicators distributed on measuring the level of employee satisfaction with distributive justice in the Jordanian companies for pharmaceutical industry. The statistical data shown in Table No. (12) indicate that the levels of satisfaction with distributive justice were high with an average of (3.43) points, and according to indicators This axis was for the indicator "Equal opportunities are available to join educational and training scholarships", the highest degree of satisfaction with an average of (3.76), followed by the indicator "Decisions are taken against employees without prejudice" with an average of (3.73).

Indicator (5), which states, "The personal capabilities of employees are taken into account when distributing tasks," received the lowest degree of satisfaction with an average of (2.93). The third axis (fairness of transactions)

This axis included (9) indicators to measure the level of employee satisfaction with the fairness of transactions in the Jordanian companies for pharmaceutical industry, where the statistical data shown in Table No. (13) indicate that the levels of satisfaction among all the expressions indicating the level of satisfaction with the fairness of transactions obtained a medium degree with an arithmetic average (3.26), and it is noted that the highest rate of employee satisfaction was on indicator (9), which states that "discrimination between employees on certain partisan or factional grounds is avoided." Highly, with a mean of (3.65), followed by the indicator that states "Employees are treated with care and respect when making decisions related to their job" with a mean of (3.46).

While the lowest satisfaction rate was for the indicator that states, "The pharmaceutical industry engages employees when reviewing and developing policies and procedures related to human resources management with clarity," with a mean of (3.04).

Fourth Axis (Training and Development)

The fourth axis included (6) indicators to measure the level of satisfaction of employees with the training process in pharmaceutical industry, where the table shows the distribution of the number of employees and response rates for each indicator and the degree of satisfaction and the general average of the axis, indicating that the levels of satisfaction among the majority of expressions indicating the level of satisfaction for training and development are moderately with an average Arithmetical (3.2), and it is noted that the highest phrase was "The pharmaceutical industry directs the new employee and educates him about the regulations, laws, and instructions approved in pharmaceutical industry upon appointment" with an average of 3.76, while the lowest percentage of satisfaction for the two phrases "The Human Resources Department determines the training needs of employees based on Performance evaluation results "The pharmaceutical industry prepares the training plan based on the training needs of the employees." With a mean of (2.99).

Fifth Axis (Motivation)

This axis included (5) indicators to measure the level of satisfaction of employees in pharmaceutical industry about the motivation and encouragement systems for employees and a reflection of their level of performance. The level of satisfaction in this axis was average and it ranked lowest among the seven axes with an average satisfaction of (2.80).

The statistical data shown in Table No. (15) indicates that the highest employee satisfaction rate was for the phrase "The pharmaceutical industry adopts specific and declared standards and foundations to ensure the application of the principle of justice and transparency in granting rewards and incentives" with a mean of (3.04), while the lowest percentage of 
satisfaction with the indicator "The pharmaceutical industry implements programs related to the well-being of employees, such as social, sports and cultural activities" with a mean of (2.15).

\section{Sixth Axis (Work Environment)}

The seventh axis included (5) indicators used to measure the level of satisfaction of employees with the work environment in pharmaceutical industry, and the statistical data shown in Table No. (16) indicate that the levels of satisfaction for all expressions indicating the satisfaction of service recipients with the axis of satisfaction with the work environment were at the level of satisfaction Average with a mean of (3.32) in general, where the highest percentage of employee satisfaction was for the phrase related to "The pharmaceutical industry is committed to maintaining the confidentiality and security of information and data related to its employees" and with a mean of (3.88), while the lowest satisfaction rate was for the phrase related to "The pharmaceutical industry is working to encourage employees to participate in community activities" with a mean of (2.84).

$7: 4$ The level of job satisfaction with the Jordanian companies for pharmaceutical industry of the employees

From the reality of analyzing the data of the study of employee satisfaction with pharmaceutical industry, and regarding the direct question that was put to the employees to find out the extent of their overall satisfaction with the level of job satisfaction with work in pharmaceutical industry.

Figure 2: Percentage of respondents to the level of satisfaction at pharmaceutical industry for the year 2021.

The figure expresses that the job satisfaction of the pharmaceutical industry's employees in total tends to the high degree, as it reached the highest percentage (20\%) at the eighth level, and this percentage falls within the high degree of the available level, as it is divided into three levels.

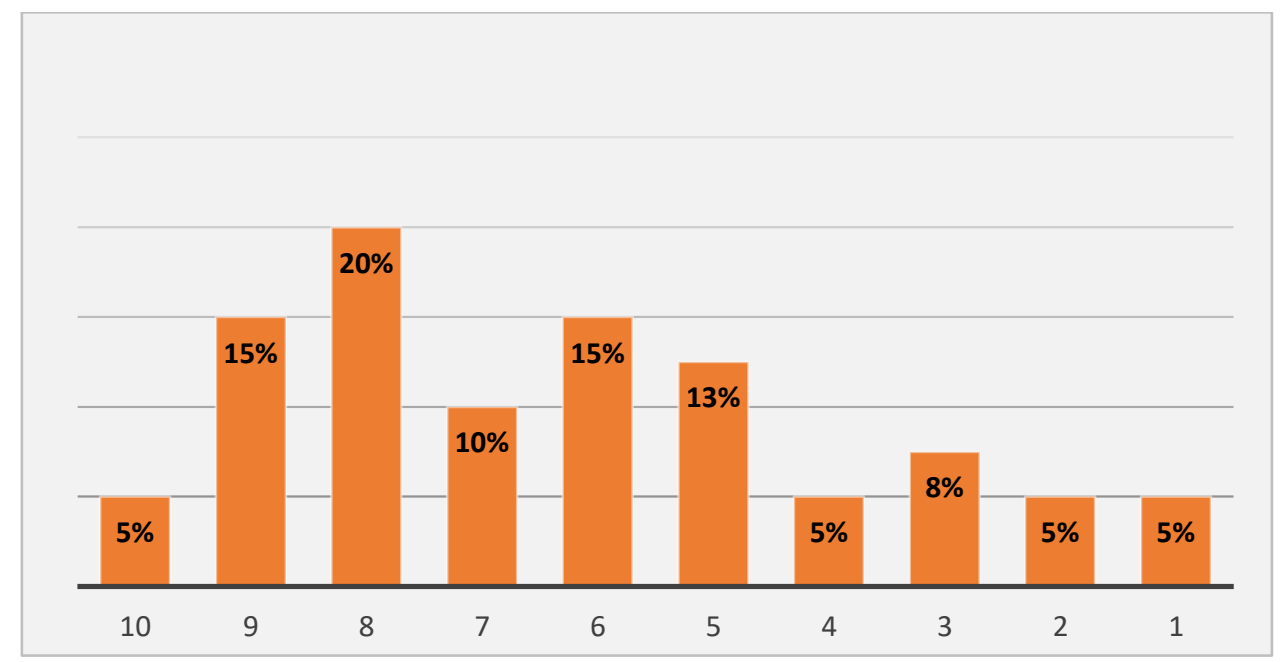

The figure above expresses that the job satisfaction of the pharmaceutical industry's employees in total tends to the high degree, as it reached the highest percentage $(20 \%)$ at the eighth level, and this percentage falls within the high degree of the available level, as it is divided into three levels. 
Knowledge of the pharmaceutical industry's vision, mission, and strategic objectives.

From the figure below, we notice that a high percentage of the pharmaceutical industry's employees are familiar with its vision, mission, and strategic objectives. The results showed that the proportion of those who had knowledge and insight into (the pharmaceutical industry's vision, mission, and strategic objectives) amounted to (96\%, 88\%), respectively, while it was the percentage of those without knowledge $(4 \%, 12 \%)$, respectively.

Figure 3: Knowledge of the pharmaceutical industry's vision and mission and strategic objectives.

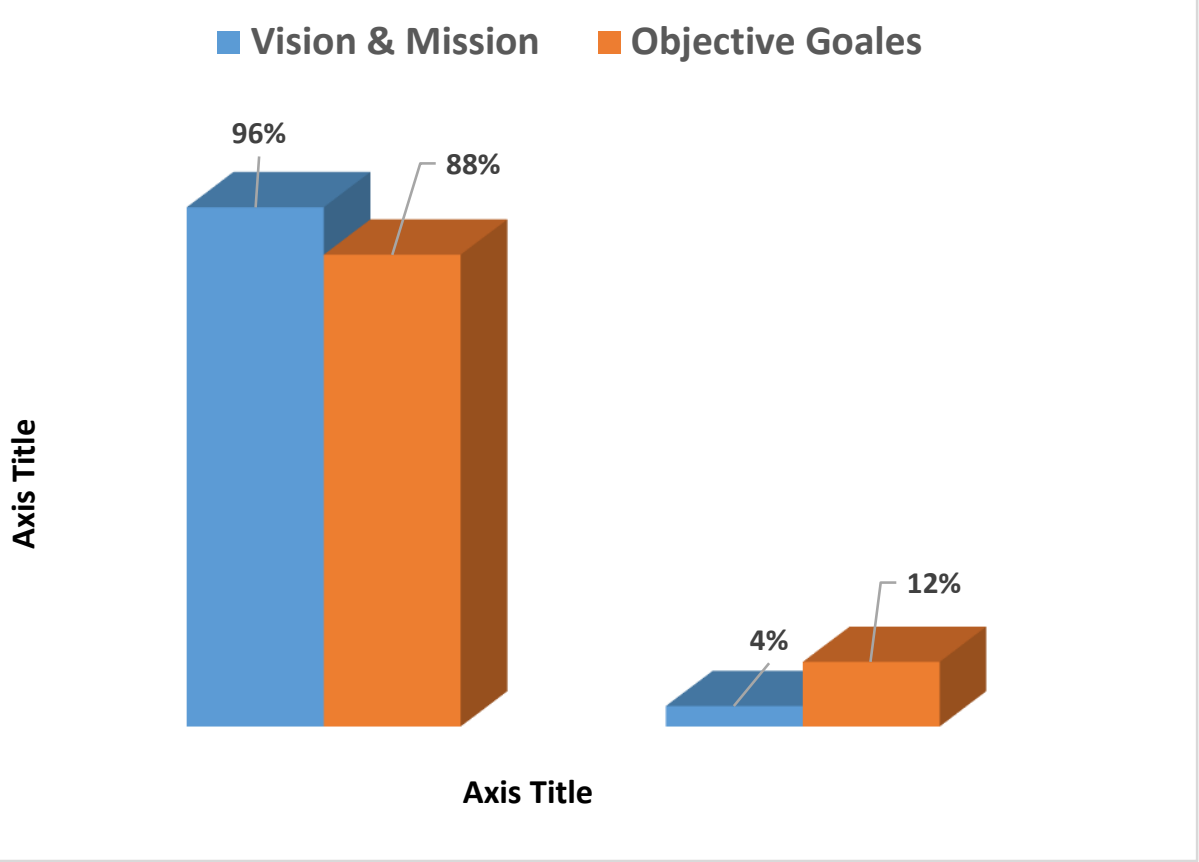

The means of knowledge of the vision, mission, and goals

The results showed that (96\%) of the employees were familiar with the vision and the mission, and the website of the pharmaceutical industry had the largest role in spreading the vision and mission of the pharmaceutical industry among the employees by (38\%) among all the means that were mentioned in the employees' answers, followed by the mail order electronic mail (25\%).

Figure 4: Relative distribution of employees according to the means of knowledge of the vision, mission, and strategic goals.

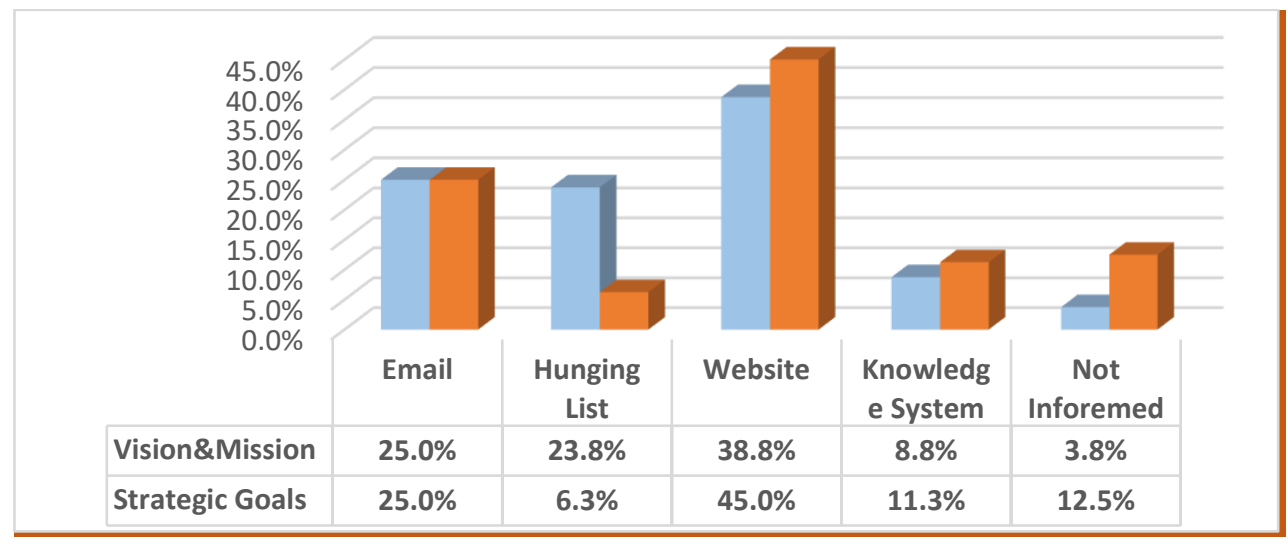




\section{The most Important Findings and Recommendations}

5.1. This part includes the presentation and discussion of the results reached by the researchers through statistical analysis, through which they were able to answer the study questions and test the hypotheses. Accordingly, the researcher presented several recommendations and results that aim to demonstrate the impact of organizational justice on job satisfaction. The results showed a summary to test the hypotheses of the study as follows:

((H0): "There is no statistically significant effect of organizational justice with its dimensions (procedural justice, distributive justice, transactional justice) at the level of significance ( $\alpha$ 0.05) on job satisfaction with its combined dimensions (training and development, motivation, work environment) among employees Civil Service Bureau"), and it was found that there is a medium degree effect between organizational justice with its dimensions (procedural justice, distributive justice, transactional justice) on job satisfaction with its combined dimensions (training and development, motivation, work environment) among the Bureau's employees, where the satisfaction rate reached (64.6\%) and with a mean of (3.18), and therefore the employee's sense of fairness and equity within the pharmaceutical industry will moderately affect his job satisfaction.

((H0-1): "There is no statistically significant effect of organizational justice with its dimensions (procedural justice, distributive justice, transactional justice) at the level of significance $(0.05 \geq \alpha)$ on training and development among Pharmaceutical industry employees"), and it was reached There is an effect of a medium degree between organizational justice with its dimensions (procedural justice, distributive justice, transactional justice) on training and development for pharmaceutical industry employees, where the arithmetic average reached (3.20), and therefore the employee feels that he has received training and development as he deserves and there is justice in dealing for all Inside the bureau, it will moderately affect his job satisfaction.

((H0-2): There is no statistically significant effect of organizational justice with its dimensions (procedural justice, distributive justice, transactional justice) at the significance level $(0.05 \geq \alpha)$ on motivation among Pharmaceutical industry employees"), and it was found that there is an effect With a medium degree between organizational justice with its dimensions (procedural justice, distributive justice, transactional justice) on motivation among Pharmaceutical industry employees, where the arithmetic average reached (2.80), and therefore the employee's sense of distributive justice in relation to granting incentives and rewards will moderately affect his job satisfaction.

((H0-3): There is no statistically significant effect of organizational justice with its dimensions (procedural justice, distributive justice, transactional justice) at the level of significance $(0.05 \geq \alpha)$ on the work environment of Pharmaceutical industry employees"), and it was found that there is The effect of a medium degree between organizational justice and its dimensions (procedural justice, distributive justice, transactional justice) on the work environment of Pharmaceutical industry employees, where the arithmetic average reached (3.32), and therefore, applying the principle of organizational justice correctly will affect moderately on his job satisfaction in relation to the environment the work. 
As a result of the previous ratios, it was found that distributive justice is the most influential dimension on job satisfaction among pharmaceutical industry employees, and the ratio was high with an average of (3.43).

\section{Recommendations}

1. Preparing a training plan based on the actual training needs of the employees, seeking to provide free, semi-free or funded training programs from other parties, and considering the time factor of the training program.

2. Empowering all employees by participating in committees, internal and external courses, and work teams formed within the Bureau, for the purposes of knowledge transfer.

3. Strengthening ties and social communication between senior management and all employees at their various levels of management through national and international meetings, meetings, and events, and taking improvement and development measures based on their feedback.

4. Periodically apply, review, and develop job descriptions in line with job changes.

5. Involve employees in preparing work plans and mechanisms that achieve the vision and mission of the Bureau, and their participation when developing and reviewing policies and procedures related to human resources management.

6. Review the foundations and distribution of rewards, in addition to raising the level of moral motivation "by letters of thanks and certificates of appreciation and distinction" according to performance and achievement, considering the personal capabilities of employees when distributing tasks.

\section{References}

Abu Libdeh. (2020). The degree of availability of dimensions of organizational justice in the directorates of education in the governorates of Gaza \& its relationship to job satisfaction from the point of view of its employees. [Unpublished master's thesis]: AlAqsa University.

Al-Anazi, M., Al-Khidr, O., \& Gad El-Rub, H. (2020). The effect of perceiving organizational justice on job satisfaction \& organizational commitment through mood \& confidence: The Arab Journal of Educational \& Psychological Sciences, 4, 245-27.

Allawi, S. (2018). Organizational justice \& its relationship to organizational citizenship. [Unpublished master's thesis]: The Ministry of Higher Education \& Scientific Research, Faculty of Humanities \& Social Sciences, Mohamed Boudiaf University.

Al-Washa'I, I., \& Al-Washa'I, M. (2020). The role of organizational justice in enhancing job stability, a field study at the headquarters of the municipality of Kouenine, [Unpublished master's thesis]: The Ministry of Higher Education \& Scientific Research, University of Martyr Hama Lakhdar El Wadi, Faculty of Social Sciences \& Humanities.

Al-Zafari, S., \& Saidia, D. (2020). Organizational silence \& its relationship to organizational justice among workers in schools in the Sultanate of Oman: Journal of Educational \& Psychological Sciences, 21, 373-401.

Belhadi, Y. (2016). The Role of the Work Environment in Achieving Job Satisfaction in Sports Institutions. [Unpublished Ph.D. thesis]: Institute of Science \& Techniques for Physical \& Sports Activities.

Brayer, A., \& Marcinowicz, L. (2018). Job satisfaction of nurses with Master of Nursing degrees in Poland: quantitative \& qualitative analysis, BMC health services research, 18, 1-7. 
Buzrin, F. (2017). The Impact of Human Resource Management Practices on Building the Competitive Advantage of Algerian Medium Enterprises, a field Study in Some Institutions in Setif State. [Unpublished PhD thesis]: Faculty of Economics, Commerce \& Management Sciences, Farhat Abbas Setif, Algeria University.

Buchta, A., \& Haj Ahmed, I. (2020). Organizational laxity \& its relationship to organizational justice, a field studies in the Directorate of Youth \& Sports, Adrar. [Unpublished master's thesis]: Faculty of Humanities, Social \& Islamic Sciences, Ahmed Deraya University.

Fadel, F. (2019). Organizational justice \& its relationship to organizational commitment \& achievement motivation among workers, a field study in the industrial complex for cement production "Zhana" - State of Mascara. (Unpublished Ph.D. thesis): Faculty of Social Sciences, University of Oran.

Gelard, P., \& Karimi, A. (2016). The effect of organizational justice \& job satisfaction on Melli Bank employee performance evaluation: Journal of Current Research in Science, 2, 671.

Ghumari, A., Ben Kahla, \& Farra, M. (2017). The motivation process \& its relationship to organizational justice, a field study "The Palestinian Police in the Gaza Strip: Journal of the Islamic University of Economic \& Administrative Studies, Scientific Research \& Graduate Studies Affairs at the Islamic University, 25, 89-107.

Hammadi, S. (2017). The Impact of Dimensions of Psychological Empowerment on Job Satisfaction \& Job Performance for Workers. An exploratory study of the opinions of a sample of workers in a number of service organizations in the city of Baghdad: Journal of Humanities of Zakho University, 5, 429-445.

Jain, M., \& Mathur, G. (2015). Effect of Organization Justice \& Employee Engagement on Job satisfaction. Organization: Journal of Social \& Human Sciences, 2.

Janibi, A. (2020). The impact of human resource management practices on employee satisfaction in public universities: a case study of the United Arab Emirates University [Unpublished master's thesis]. College of Humanities \& Social Sciences.

Osman, A., \& Ali, S. (2019). The Impact of Organizational Justice on the Organizational Loyalty of Employees, [Unpublished master's thesis]. Graduate Studies at Sudan University of Science \& Technology.

Qujah, R., \& Khairy, A. (2020). Socio-organizational reading of the relationship of organizational loyalty to worker's job satisfaction: Journal of Social \& Human Sciences. 9, 219-244.

Reah, G. (2018). Job Satisfaction among Basic Stage Teachers \& its Impact on Improving Professional Performance: Case Study, Quality Foundation Schools, Khartoum. [Unpublished master's thesis]. College of Graduate Studies, Sudan University of Science \& Technology.

Safa', J., \& Al-Shurman, M., (2014). The degree of job satisfaction for faculty members at Mutah University \& its relationship to their level of job performance: Al-Manara Journal of Yarmouk University, 20, 411-444.

Shamma, F. (2019). The degree of job satisfaction among teachers of Arab public schools within the Green Line: Journal of the Islamic University of Educational \& Psychological Studies. Ministry of Education within the Green Line, 5, 450-467. 